\title{
New Paraquat Requirements ${ }^{1}$
}

\author{
Fred Fishel, Brett Bultemeier, and Jay Ferrell²
}

This document will address the mitigation measures being undertaken by the EPA, which became new labeling requirements for all paraquat products November 14, 2019.

\section{What is paraquat?}

Paraquat dichloride, commonly referred to as "paraquat," is one of the most widely used herbicides registered in the United States. Paraquat is sold under several brand names, one of which is the popular product, Gramoxone ${ }^{\circledast}$ SL 2.0. Although commonly used, it is one of the most acutely toxic pesticides commonly on the market with a $\mathrm{LD}_{50}$ value of only 3 to $5 \mathrm{mg} / \mathrm{kg}$ in humans. To put this in perspective, this translates into as little as 10 to $15 \mathrm{ml}$ of a $20 \%$ solution.

\section{What are paraquat's use patterns?}

Paraquat is used to control weeds in many agricultural and non-agricultural use sites. It is also used as a defoliant on crops such as cotton prior to harvest. There are no homeowner uses and no products registered for application in residential areas. All paraquat products registered for use in the United States are Restricted Use Pesticides (RUPs), which can only be sold to and used by certified and licensed applicators.

\section{Why is the EPA taking mitigation measures with paraquat?}

The EPA noted in 2016 that the illegal transfer of paraquat to beverage containers resulted in accidental ingestions that led to the deaths of 17 people since 2000. Three of those who died were children. In all of these cases, someone put paraquat into a drink bottle, which led to the death of someone else. Because of paraquat's acute toxicity to humans, one small sip can be fatal, and there is no antidote. Data also suggest that paraquat is corrosive to the skin and eyes. Since 2000, three deaths and a high number of severe injuries have been caused by paraquat getting onto the skin or into the eyes of workers handling paraquat.

\section{What are the specific mitigation measures that will be put into effect with paraquat?}

In order to mitigate some of the issues with paraquat, EPA is requiring some changes. These include:

- New, closed-system packaging designed to prevent transfer or removal of the pesticide except directly into proper application equipment. This will prevent spills, mixing, pouring the pesticide into other containers, or other actions that could lead to paraquat exposure.

- Specialized training for certified applicators who use paraquat to emphasize that the chemical should not be transferred to or stored in improper containers.

- Changes to the pesticide label and distribution of supplemental warning materials to highlight the toxicity and risks associated with paraquat products.

- Restricting the use of paraquat to certified pesticide applicators only. Unlicensed individuals working under

1. This document is PI279, one of a series of the Agronomy Department, UF/IFAS Extension. Original publication date November 2018. Revised December 2019. Visit the EDIS website at https://edis.ifas.ufl.edu for the currently supported version of this publication.

2. Frederick M. Fishel, professor; Brett Bultemeier; and Jay Ferrell, professor; Agronomy Department; UF/IFAS Extension, Gainesville, FL 32611.

The Institute of Food and Agricultural Sciences (IFAS) is an Equal Opportunity Institution authorized to provide research, educational information and other services

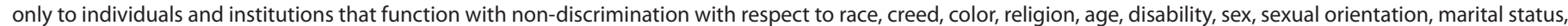

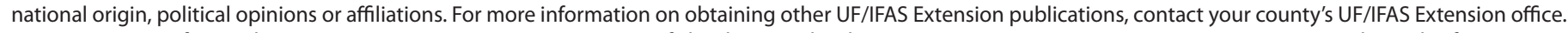
U.S. Department of Agriculture, UF/IFAS Extension Service, University of Florida, IFAS, Florida A \& M University Cooperative Extension Program, and Boards of County Commissioners Cooperating. Nick T. Place, dean for UF/IFAS Extension. 
the supervision of a certified applicator are prohibited from using paraquat.

\section{What are the closed-system requirements?}

The closed-system requirement only applies to non-bulk end-use paraquat products, such as packaged product commonly available in 1- and 2.5-gallon packages. Persons other than registrants may continue to sell and/or use existing stocks of paraquat products with the previously approved labeling until such stocks are exhausted, provided that such use is consistent with the terms of the previously approved labeling and the current state registration remains in effect for the specific brand.

\section{What is going to be involved with the mandatory training for paraquat use?}

The paraquat training program is a key component of EPA's efforts to prevent accidental ingestion of paraquat. All mixers, loaders, handlers, and applicators of paraquat products are required to successfully complete the training. This certification must be renewed every three years. The EPAapproved paraquat training is available online by accessing https://campus.extension.org/enrol/index.php?id=1660.

The training consists of five key points:

- The acute toxicity of paraquat through all routes of exposure

- Emphasis on never transferring paraquat into another container

- Examples and consequences of misuse of paraquat

- What to do in case of accidental exposure to paraquat

- A summary of what has changed as a result of the paraquat human health mitigation decision

Once training is completed, the mixer, loader, handler or the applicator must maintain a record of their successful completion. The training system will generate a certificate as part of the completion process.

\section{Why isn't the EPA-mandated paraquat certification being offered in Spanish?}

This is linked to the pesticide license requirements, which require a person to successfully complete the exams in English in order to prove they can review and understand product labels, which are only offered in English.

\section{What amendments will occur to paraquat product labels?}

There will be additions to existing product labels. Additions to the product labels include:

- Statements highlighting paraquat toxicity

- The "Certified Applicator Only" statement

- The EPA-approved paraquat training program statement. This statement will include a link to the on-line training.

There will also be some supplemental materials made available. These materials will be in English, Spanish, and pictogram format. They include:

- Product Package Safety Requirements stickers on each paraquat container on the side opposite the label

- Counter cards with warning information for people who purchase paraquat

- A cap sticker with a warning statement and the skull and crossbones pictogram

In Florida, I thought that a certified and licensed agricultural applicator may provide direct supervision to up to 15 unlicensed employee applicators. How is this changing?

That is correct with practically all RUPs; however, paraquat will now be an exception. As previously stated, only certified mixers, loaders, handlers, and applicators who successfully complete an EPA-approved training program and hold a valid pesticide applicator license in Florida will be able to legally handle paraquat. This will be a requirement in all states.

Are retailers and growers allowed to continue to sell and use paraquat formulations that do not carry the new paraquat mitigation measures?

Retailers, growers and custom applicators can use existing stocks until they are depleted or until the state registration is canceled by the registrant. After $11 / 14 / 19$, any product 
manufactured and offered for sale must contain the new paraquat mitigation language and requirements. The closed system requirement doesn't go into effect until sometime in 2020. At some point during 2020, there will be both "old" product and "new" product in the commercial channel. If a grower happens to comingle old and new product in their operation, the old product MUST be used according to the new guidelines. 